J. Lake Sci.(湖泊科学), 2019, 31(3): 837-845

DOI 10. 18307/2019. 0321

(c) 2019 by Journal of Lake Sciences

\title{
三峡水库与长寿湖水库鱼类碳、氮稳定同位素特征及营养级的比较
}

\author{
谢 青 ${ }^{1}$, 徐勤勤 ${ }^{1}$, 王永敏 ${ }^{1,2,3}$, 孙 涛 $^{1}$, 焚宇飞 ${ }^{1}$, 刘伟豪 ${ }^{1}$, 王定勇 ${ }^{1,2,3 * *}$ \\ (1:西南大学资源环境学院,重庆 400715) \\ (2:重庆市三峡库区农业面源污染控制工程技术研究中心,重庆 400716) \\ ( 3 : 重庆市农业资源与环境研究重点实验室,重庆 400716)
}

\begin{abstract}
摘 要: 为探究人为活动对水库鱼类食物来源和营养级关系的影响,选择人为影响程度较低的三峡水库和影响程度较高 的长寿湖水库为研究对象, 应用碳、氮稳定同位素技术对两个水库鱼类 $\delta^{13} \mathrm{C}$ 值、 $\delta^{15} \mathrm{~N}$ 值和营养级进行比较分析. 结果显 示: 长寿湖水库鱼类 $\delta^{13} \mathrm{C}$ 平均值 $(-22.66 \% \pm 1.94 \%)$ 与三峓水库 $\left(-22.59 \% \pm 1.87 \% 0\right.$ ) 较为接近, 但长寿湖鱼类的 $\delta^{15} \mathrm{~N}$ 值 $(13.95 \% \pm \pm 3.02 \% 0)$ 显著高于三峡水库鱼类的 $\delta^{15} \mathrm{~N}$ 值 $(11.98 \% 0 \pm 2.25 \% 0)$. 根据 $\delta^{15} \mathrm{~N}$ 值计算不同食性鱼类间的营养级， 三峡水库营养级为肉食性鱼类>杂食性鱼类 $>$ 浮游生物食性鱼类 $>$ 草食性鱼类; 而长寿湖中则表现为浮游生物食性鱼类> 肉食性鱼类>杂食性鱼类>草食性鱼类, 营养级出现了异常现象. 这一结果表明, 对于人为影响 (如人工喂食鱼饲料等) 较 大的水体,采用 $\delta^{15} \mathrm{~N}$ 值计算不同食性鱼类间的营养级存在不确定性.
\end{abstract}

关键词: 碳、氮稳定同位素;营养级;三峡水库;长寿湖水库;鱼类

\section{Stable isotope value and trophic position of fishes in Three Gorges Reservoir and Chang- shou Reservoir}

XIE Qing ${ }^{1}$, XU Qinqin ${ }^{1}$, WANG Yongmin ${ }^{1,2,3}$, SUN Tao $^{1}$, FAN Yufei ${ }^{1}$, LIU Weihao ${ }^{1} \&$ WANG Dingyong $^{1,2,3 * *}$

(1: College of Resources and Environment, Southwest University, Chongqing 400715, P.R.China)

(2: Chongqing Engineering Research Center for Agricultural Non-Point Source Pollution Control in the Three Gorges Reservoir Area, Chongqing 400716, P.R.China)

(3: Chongqing Key Laboratory of Agricultural Resources and Environment, Chongqing 400716, P.R. China)

\begin{abstract}
To investigate the effect of the food sources and trophic position of fish in different anthropogenic interference of Three Gorges Reservoir ( TGR) and Changshou Reservoir, we used stable isotopes analysis to investigate the $\delta^{13} \mathrm{C}$ and $\delta^{15} \mathrm{~N}$ signatures of fish in these two reservoirs. Meanwhile, differences in isotopic values and trophic position of fish were also compared. The result showed that little variation in $\delta^{13} \mathrm{C}$ values of fish was observed between TGR and Changshou Reservoir. The average $\delta^{13} \mathrm{C}$ values of fish observed in Changshou Reservoir $\left(-22.66 \% \pm \pm 1.94 \%\right.$ ) was similar to that in TGR $\left(-22.59 \%\right.$. $1.87 \%$ ). While, the $\delta^{15} \mathrm{~N}$ values of fish in Changshou Reservoir ( $13.95 \% \pm \pm 3.02 \%$ ) were significantly higher than that in TGR ( $11.98 \% \pm 2.25 \%$ ) . We calculated the trophic level among different fishes based on the value of $\delta^{15} \mathrm{~N}$. The trophic level decreased in order of carnivorous fish > omnivorous fish > planktivore fish > herbivorous fish in TGR. While, a relative difference was occurred at Lake Changshou in terms of the trophic level which was conducted as planktivore fish $>$ carnivorous fish $>$ omnivorous fish $>$ herbivorous fish when compared with those in TGR. The result indicated the uncertainty of trophic level derived from value of $\delta^{15} \mathrm{~N}$ for aqueous systems with intensive influences of human activities.
\end{abstract}

Keywords: Carbon and nitrogen stable isotopes; trophic position; Three Gorges Reservoir; Changshou Reservoir; fish

* 国家自然科学基金项目 (41373113,41603103)、中央高校基本科研业务费专项(XDJK2017B035)和国家重点基础 研究发展计划“973”项目(2013CB430004) 联合资助. 2018-09-12 收稿; 2018-11-08 收修改稿. 谢青 ( 1993 ), 女,博士研究生;E-mail: cqxqing@163.com.

** 通信作者;E-mail :dywang@ swu.edu.cn. 
水生态系统中营养关系和食物网结构的研究对于深人理解生态系统结构与功能十分重要 ${ }^{[1,2]}$. 研究营 养关系和食物网结构的传统方法主要为胃含物分析法, 属于食性分析法, 其结果偏向于较难消化的食物, 不 能提供长期的摄食信息及食性转化情况, 且难以判断捕食者胃含物的消化吸收程度, 存在较大的不确定 性 ${ }^{[3-4]}$. 而稳定同位素作为一种天然示踪物, 为研究生态系统中各生物种群之间的摄食关系、营养层次和能 量流动提供了新的技术手段 ${ }^{[5-7]}$, 已被广泛应用于水域生态系统营养关系和食物网结构的研究中 ${ }^{[8-10]}$.

不同生境及人类活动的扰动导致鱼类营养级和食物网结构存在较大不确定性 ${ }^{[11]}$. 人类活动产生的有 机污染物和水生生物的排泄物均含有相对较高的 ${ }^{15} \mathrm{~N}$ 同位素比例 ${ }^{[12-14]}$, 从而影响浮游植物、浮游动物等生物 的 $\delta^{15} \mathrm{~N}$ 值. 张欢等 ${ }^{[15]}$ 对鄱阳湖流域的研究发现, 人类活动是饶河不同区域鱼类氮稳定同位素比值存在明显 差异的主要原因. 此外, 水库网箱养鱼投放的鱼饵料中含有的鱼骨粉和谷物蛋白等物质也会影响鱼类的氮 同位素值, 从而导致鱼类营养级异常 ${ }^{[16]}$.

三峡水库作为举世瞩目的特大调节型水库, 为保护水质, 人工水产养殖活动被禁止, 其水生食物链可被 认为人为扰动相对较小. 长寿湖水库由于 20 世纪网箱养鱼大量饲料的投放, 化肥、鸡粪和周边居民生活污 水等的排人,生态环境受到了严重的人为干扰 ${ }^{[17]}$. 研究表明, $\delta^{15} \mathrm{~N}$ 在营养级间逐层富集, 人为扰动如氮源污 染可使海洋鱼体 $\delta^{15} \mathrm{~N}$ 值异常 ${ }^{[18-19]}$, 营养级发生错乱, 导致无法准确判断其营养级和食物网结构 ${ }^{[20]}$. 而受人 为干扰严重的长寿湖水库的鱼类营养级及食物网结构的变化尚不明确.

本研究通过比较三峡水库和长寿湖水库鱼类 $\delta^{13} \mathrm{C} 、 \delta^{15} \mathrm{~N}$ 值和营养级的差异, 探究人为干扰对水生态系 统食物网结构的影响, 以期为准确判断水生态系统食物网结构提供科学依据.

\section{1 材料与方法}

\section{1 研究区概况}

三峡水库是三峡大坝建成后蓄水形成的湖泊,水域面积 $1084 \mathrm{~km}^{2}$, 流经重庆市和湖北省的 21 个县市. 自 2006 年三峡大坝正式建成以来, 水库沿岸居民已全数搬迁, 当前三峡水库鱼类受人为活动影响较小, 其

表 1 三峡水库与长寿湖水库水体理化指标

Tab.1 Water physicochemical characteristics in Three Gorges Reservoir and Changshou Reservoir

\begin{tabular}{lll}
\hline 水质参数 & 三峡水库 & 长寿湖水库 \\
\hline 总氮 $/(\mathrm{mg} / \mathrm{L})$ & $0.58 \sim 1.67$ & $0.55 \sim 2.71$ \\
总磷 $/(\mathrm{mg} / \mathrm{L})$ & $0.005 \sim 0.08$ & $0.02 \sim 0.25$ \\
叶绿素 $\mathrm{a} /(\mu \mathrm{g} / \mathrm{L})$ & $0.94 \sim 28.90$ & $3.44 \sim 178.92$ \\
溶解氧 $/(\mathrm{mg} / \mathrm{L})$ & $7.93 \sim 9.50$ & $6.56 \sim 11.38$ \\
$\mathrm{pH}$ 值 & $7.32 \sim 8.39$ & $7.17 \sim 8.95$ \\
\hline
\end{tabular}
中鱼类生长的生态条件接近天然环境. 较少的生活 污水及农业废水等污染源的输人, 使得三峡水库水 体的营养化水平相对较低 (表 1). 长寿湖水库 $\left(29^{\circ}\right.$ $54^{\prime} \sim 30^{\circ} 50^{\prime} \mathrm{N}, 107^{\circ} 14^{\prime} \sim 107^{\circ} 25^{\prime} \mathrm{E}$ ) 位于重庆市长寿 区境内 (图 1), 是重庆市最大的人工湖泊, 被人为划 分成旅游、农业、养殖、发电等功能区. 长寿湖水库一 直以来受到较为严重的人为活动干扰. 网箱养鱼大 量投放饲料、化肥和鸡粪等, 导致水体处于严重富营 养化状态. 虽然现在已经拆除水库的网箱、停止围网 养鱼,但目前仍处于富营养化状态 (表 1).

\section{2 样品采集与测定}

本研究分别于三峡水库 (忠县石宝寨和涂井、涪陵珍溪)、长寿湖水库采集鱼类和浮游动物样品 (图 1). 鱼类样品均来自当地渔民直接捕捞或垂钓, 将采集的鱼样现场密封充氧气后运回实验室进行前处理: 常温 下将鱼样分类平推拍照并鉴定其种类, 测量并记录鱼体体长和体重 ( 附录 I ). 用纯水将鱼体洗净, 取其第一 背鯺附近肌肉, 用去离子水清洗, 在真空干燥仪中冷冻干燥至恒重, 使用研针研至均匀粉末, 干燥保存. 浮游 动物样品采集利用 $13^{\#}$ 浮游生物网 ( 孔径 $112 \mathrm{~mm}$ ), 在表层水中拖网捕集 $30 \mathrm{~min}$. 采集完成后立即将样品送 回实验室, 放人装有蒸馏水的烧杯中, 在 $15 \sim 25^{\circ} \mathrm{C}$ 条件下清养 $5 \mathrm{~h}$, 以清空浮游动物肠道的内含物, 随即在解 剖镜下挑取浮游动物至锡囊中, 然后在真空干燥仪中冷冻干燥样品至恒重, 使用研针研至均匀粉末, 干燥保 存. 所有样品的稳定同位素比值均采用稳定同位素质谱仪 (IsoPrime 100, 德国) 和元素分析仪 (Elementar Pyro Cube, 德国) 测定分析计算. 采集的水样现场加人 $1 \mathrm{ml}$ 体积比为 $1: 1$ 的硫酸溶液固定保存, 并及时带回 实验室分析总氮、总磷和叶绿素 a 浓度 ${ }^{[21-22]}, \mathrm{pH}$ 值由美国 Sartorius 公司 PT-10 便携式测定仪现场测定, 溶解 氧浓度由美国 YSI 公司 $550 \mathrm{~A}$ 便携式溶解氧仪现场测定. 


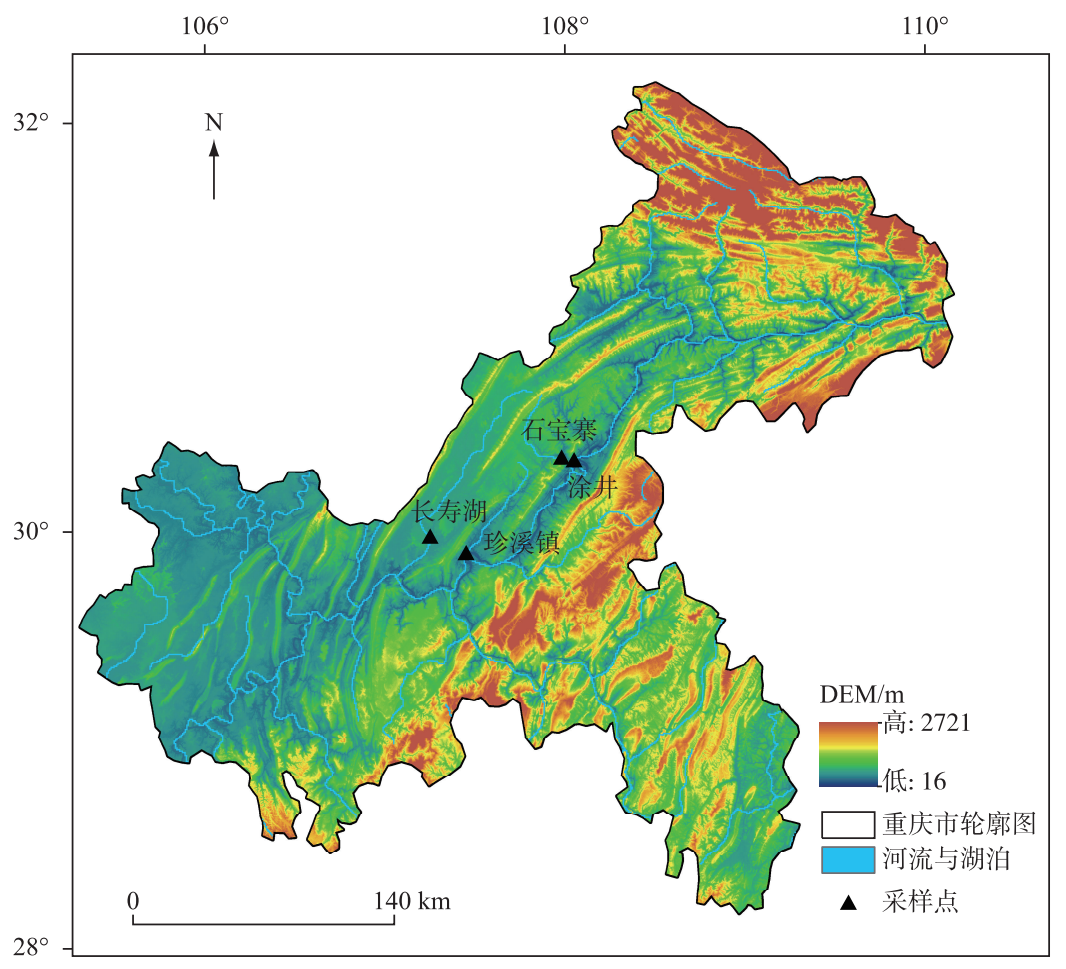

图 1 采样点概况

Fig.1 A schematic diagram of sampling sites

\section{3 数据处理与分析}

碳、氮稳定同位素值分别以拟箭石 (VPDB) 中的碳和纯化的大气中的 $\mathrm{N}_{2}$ 作为参考标准. 稳定同位素比 值, 即 $\delta$ 值, 其定义为:

$$
\delta X(\%)=\left(R_{\text {sample }} / R_{\text {standard }}-1\right) \times 1000
$$

式中, $X$ 为 ${ }^{13} \mathrm{C}$ 或者 ${ }^{15} \mathrm{~N}, R$ 为 ${ }^{13} \mathrm{C} /{ }^{12} \mathrm{C}$ 或者 ${ }^{15} \mathrm{~N} /{ }^{14} \mathrm{~N}$ 的比值. 为确保试验结果的精度和准确度, 每 10 个样品插人 标准样品 (USGS24、USGS25), 分析精度为 $\delta^{13} \mathrm{C}<0.20 \%, \delta^{15} \mathrm{~N}<0.30 \%$.

消费者和食物间的 $\delta^{15} \mathrm{~N}$ 差异就是营养分馏值, 随着营养级增加 $\delta^{15} \mathrm{~N}$ 不断增加, 不同营养级间的 $\delta^{15} \mathrm{~N}$ 富 集的平均值为 $3.4 \%{ }^{[23]}$. 营养级计算公式为:

$$
T L=\left(\delta^{15} \mathrm{~N}_{\text {consumer }}-\delta^{15} \mathrm{~N}_{\text {baseline }}\right) / \Delta^{15} \mathrm{~N}+\lambda
$$

式中, $\Delta^{15} \mathrm{~N}=3.4 \%$, 当 baseline 是生产者时, $\lambda=1$; 当 baseline 是初级消费者时, $\lambda=2$. 其中基线生物选择的准 确性对于评估消费者营养级位置至关重要, 本文分别选取两个水库的浮游动物作为基线评价鱼类营养级位 置. 其中三峡水库中浮游动物氮稳定同位素值为 $6.92 \%$; 长寿湖水库中浮游动物氮稳定同位素值为 $6.61 \%$.

采用单因素方差分析 (ANOVA), 分别对长寿湖水库与三峡水库不同种类和不同食性鱼类的 $\delta^{13} \mathrm{C} 、 \delta^{15} \mathrm{~N}$ 以及营养级进行差异性检验. 采用线性回归对鱼类的体长与营养级进行相关性关系分析. 数据的计算与处 理均通过 Microsoft Excel 2010 和 $\operatorname{SPSS}(21.0)$ 软件进行, 置信度为 $P<0.05$.

\section{2 结果与分析}

\section{1 碳、氮稳定同位素值}

$\delta^{13} \mathrm{C}$ 常用来判断生态系统中消费者的食物来源 ${ }^{[24-25]}$, 不同食物来源的 $\delta^{13} \mathrm{C}$ 存在差异. 三峡水库 68 个鱼 类样品,包括肉食性鱼类 5 种, 分别为趐嘴红鲌 (Erythroculter ilishaeformis)、长吻鮸( Leiocassis longirostris)、鳡 
(Elopichthys bambusa)、鳜 (Siniperca chuatsi) 和鳤 (Ochetobius elongatus); 杂食性鱼类 6 种, 分别为铜鱼 (Coreius heteodon)、赤眼鳟( Squaliobarbus curriculus)、鲫( Carassius auratus)、鲤( Cyprinus carpio)、黄槡鱼 (Pelteobagrus fulvidraco) 和中华倒刺鲃 (Spinibarbus sinensis); 浮游生物食性鱼类 2 种, 分别为鳙 (Aristichthys nobilis) 和鲢 (Hypophthalmichthys molitrix); 草食性鱼类 2 种, 分别为武昌鱼 (Megalobrama amblycephala) 和草 鱼(Ctenopharyngodon idellus). 碳氮稳定同位素比值表明, $\delta^{13} \mathrm{C}$ 范围为 $-26.45 \%$ - 17.76\%o, 最大相差 $8.69 \%$. 不同食性鱼类碳稳定同位素比值间差异不显著 $(F=2.11, P>0.05)$, 但草食性鱼类的 $\delta^{13} \mathrm{C}$ 值 $(-21.45 \% 0 \pm$ $2.73 \% 0)$ 显著高于肉食性鱼类 $(-23.34 \% 0 \pm 0.95 \% 0)$ 和浮游生物食性鱼类 $(-23.21 \% 0 \pm 1.18 \% 0)$ 的 $\delta^{13} \mathrm{C}$ 值 $($ 图 2$)$ $(P<0.05)$. 说明草食性鱼类和肉食性、浮游生物食性鱼类的食物来源有很大的不同. 有研究表明, 水生植物 $\delta^{13} \mathrm{C}$ 值较高, 并且沉水植物的 $\delta^{13} \mathrm{C}$ 值明显高于挺水植物和浮叶植物 ${ }^{[26-28]}$, 本研究中三峡水库的草食性鱼类 大多是武昌鱼,生活在湖泊、河流的中下层, 主要以湖泊或河流中的沉水植物为食 ${ }^{[29]}$. 此外, $\delta^{13} \mathrm{C}$ 值随着生 物栖息的水层深度增加而增大, 生物的 $\delta^{13} \mathrm{C}$ 值由中上层向底层逐渐增加 ${ }^{[30]}$, 因此草食性鱼类的 $\delta^{13} \mathrm{C}$ 值较 高. 三峡水库鱼类 $\delta^{15} \mathrm{~N}$ 值的范围为 6.94\%0 15.34\%o, 相差较大, 但大部分 $\delta^{15} \mathrm{~N}$ 值集中在 $11 \% \%_{0} \sim 14 \% 0$ 之间, 其 中最大值出现在肉食性鱼类的长吻鮠鱼 $(15.34 \% 0)$, 最小值出现在草食性鱼类的草鱼 (6.94\%o) (表 2). 不同 食性鱼类 $\delta^{15} \mathrm{~N}$ 值存在极显著差异 $(F=16.43, P<0.01)$, 表现为肉食性鱼类 $(14.40 \% 0 \pm 0.60 \%$ ) 最大, 杂食性 鱼类 $(11.44 \% 0 \pm 2.14 \% 0)$ 和浮游生物食性鱼类 $(11.18 \% 0 \pm 0.88 \% 0)$ 次之, 草食性鱼类最小 $(9.71 \% 0 \pm 2.64 \% 0)$ ( 图 2 ), 从草食性鱼类到肉食性鱼类 $\delta^{15} \mathrm{~N}$ 值逐渐增加. 这与前人研究得到的鱼体 $\delta^{15} \mathrm{~N}$ 值随其营养层次的升高而 增加的结果类似, 甚至发现凶猛的肉食性鱼类 $\delta^{15} \mathrm{~N}$ 值超过草食性鱼类的 2 倍 ${ }^{[31]}$, 说明鱼体在沿食物链的传 递过程中能对 ${ }^{15} \mathrm{~N}$ 产生富集 ${ }^{[32]}$.

表 2 三峡水库鱼类样品的碳、氮稳定同位素比值

Tab.2 Carbon and nitrogen isotopic values of the fish samples from Three Gorges Reservoir

\begin{tabular}{|c|c|c|c|c|c|c|c|}
\hline \multirow{2}{*}{ 食性 } & \multirow{2}{*}{ 种类 } & \multirow{2}{*}{$n$ /尾 } & \multicolumn{2}{|c|}{$\delta^{13} \mathrm{C} / \%$} & \multicolumn{2}{|c|}{$\delta^{15} \mathrm{~N} / \%$} & \multirow{2}{*}{ 营养级 } \\
\hline & & & 平均值 & 范围 & 平均值 & 范围 & \\
\hline \multirow[t]{5}{*}{ 肉食性 } & 尧嘴红鲌 & 8 & $-23.15 \pm 1.06$ & $-24.47 \sim-21.58$ & $14.23 \pm 0.81$ & $13.12 \sim 15.10$ & $4.14 \pm 0.24$ \\
\hline & 鳜 & 1 & -22.18 & - & 14.54 & - & 4.24 \\
\hline & 长吻鮸 & 1 & -24.66 & - & 15.34 & - & 4.47 \\
\hline & 䱻 & 4 & $-23.24 \pm 0.31$ & $-23.46 \sim-23.02$ & $14.43 \pm 0.08$ & $14.38 \sim 14.55$ & $4.20 \pm 0.02$ \\
\hline & 稣 & 1 & -22.95 & - & 14.39 & - & 4.19 \\
\hline \multirow[t]{6}{*}{ 杂食性 } & 鲫 & 6 & $-21.31 \pm 0.39$ & $-21.87 \sim-21.01$ & $10.52 \pm 0.71$ & $9.94 \sim 11.89$ & $3.05 \pm 0.21$ \\
\hline & 鲤 & 5 & $-20.57 \pm 1.28$ & $-21.55 \sim-18.70$ & $10.17 \pm 2.68$ & $7.77 \sim 12.58$ & $2.95 \pm 0.79$ \\
\hline & 黄颡鱼 & 4 & $-24.15 \pm 2.04$ & $-26.45 \sim-22.57$ & $13.36 \pm 0.36$ & $12.83 \sim 13.60$ & $3.89 \pm 0.11$ \\
\hline & 铜鱼 & 8 & $-24.55 \pm 1.08$ & $-26.08 \sim-23.66$ & $13.82 \pm 1.42$ & $11.60 \sim 15.22$ & $4.02 \pm 0.42$ \\
\hline & 赤眼鳟 & 6 & $-21.97 \pm 1.38$ & $-23.34 \sim-20.59$ & $10.15 \pm 0.98$ & $8.80 \sim 10.94$ & $2.94 \pm 0.29$ \\
\hline & 中华倒刺鲃 & 4 & $-20.27 \pm 3.55$ & $-22.78 \sim-17.76$ & $9.37 \pm 0.35$ & $9.04 \sim 9.69$ & $2.71 \pm 0.10$ \\
\hline \multirow[t]{2}{*}{ 浮游生物食性 } & 鳙 & 4 & $-22.74 \pm 1.27$ & $-24.09 \sim-21.58$ & $12.07 \pm 0.86$ & $11.20 \sim 13.25$ & $3.51 \pm 0.25$ \\
\hline & 鲢 & 9 & $-23.45 \pm 1.18$ & $-24.48 \sim-21.87$ & $10.79 \pm 0.57$ & $10.09 \sim 11.95$ & $3.13 \pm 0.17$ \\
\hline \multirow[t]{2}{*}{ 草食性 } & 草鱼 & 3 & $-19.91 \pm 2.84$ & $-21.92 \sim-17.90$ & $7.34 \pm 0.35$ & $6.94 \sim 7.58$ & $2.12 \pm 0.10$ \\
\hline & 武昌鱼 & 4 & $-20.87 \pm 0.38$ & $-21.13 \sim-20.43$ & $12.08 \pm 0.64$ & $11.46 \sim 12.74$ & $3.51 \pm 0.11$ \\
\hline
\end{tabular}

长寿湖水库共采集鱼样 54 个,包括肉食性鱼类 3 种, 分别为尧唃红鲌、鲊和鲶 (Silurus asotus); 杂食性鱼类 4 种, 分别为鲫、鲤、黄颡鱼和胭脂鱼 (Myxocyprinus asiaticus); 浮游生物食性鱼类 2 种, 分别为鳙和鲢; 草食性鱼 类 2 种, 分别为武昌鱼和草鱼. $\delta^{13} \mathrm{C}$ 值范围为 $-26.54 \% 0 \sim-17.03 \%$, 最大相差 $9.51 \% 0$ (表 3 ), 相差较大, 范围较 广, 这可能与长寿湖鱼类广泛的摄食食物来源有关. 长寿湖水库受人为影响程度较大, 除了浮游生物等内源性 食物来源外, 还包含了陆源性动植物碎屑以及人为投放的鱼饲料等. 不同食性鱼类 $\delta^{13} \mathrm{C}$ 值存在极显著差异 $(F=14.07, P<0.01)$, 其中草食性鱼类的 $\delta^{13} \mathrm{C}$ 值 $\left(-20.18 \% 0 \pm 2.73 \%\right.$ ) 最高, 浮游生物食性鱼类的 $\delta^{13} \mathrm{C}$ 值最低 $(-25.31 \% 0 \pm 1.04 \% 0), \delta^{13} \mathrm{C}$ 值的大小规律表现为草食性鱼类>杂食性鱼类 $>$ 肉食性鱼类 $>$ 浮游生物食性鱼类. 长 
寿湖鱼类 $\delta^{15} \mathrm{~N}$ 值的范围为 $6.63 \% 0 \sim 19.15 \%$, 相差较大. 不 同食性鱼类 $\delta^{15} \mathrm{~N}$ 值存在极显著差异 $(F=6.39, P<0.01)$, 且 浮游生物食性鱼类 $(16.23 \% 0 \pm 1.69 \%$ ) 最大, 其次是肉食性 鱼类 $(15.06 \% 0 \pm 2.68 \% 0)$, 再次是杂食性鱼类 $(12.33 \% 0 \pm$ $2.70 \%$ ) , 草食性鱼类 $(11.80 \% 0 \pm 2.24 \%$ ) 最小 (图 2), 这与三 峡水库中不同食性鱼类 $\delta^{15} \mathrm{~N}$ 值表现出的规律有所不同.

三峡水库和长寿湖水库鱼类的平均 $\delta^{13} \mathrm{C}$ 值分别为

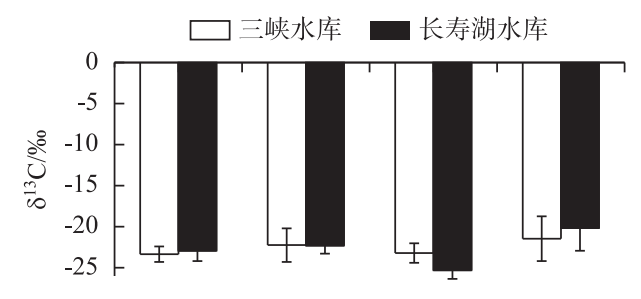
$-22.59 \% 0 \pm 1.87 \%$ 和 $-22.66 \% 0 \pm 1.94 \%$, 单因素方差分析表明 两者没有显著差异, 但两个水库同种鱼类间 $\delta^{13} \mathrm{C}$ 值存在差 异, 特别是浮游生物食性的鳙与鲢表现最为显著 $(F=$ $12.45, P<0.01)$. 三峡水库中采集的浮游生物食性鱼类 $\delta^{13} \mathrm{C}$ 值为 $-23.21 \% 0 \pm 1.18 \%$, 而长寿湖水库采集的同种鱼类 $\delta^{13} \mathrm{C}$ 值为 $-25.31 \% 0 \pm 1.04 \%$, 显著低于三峡水库 $(P<0.05)$, 表明不同生活环境鱼类食物来源存在较大的差异. 浮游生 物食性的鳙与鲢主要以水体中浮游生物等内源性的物质为 食, 其中长寿湖较大程度的人为活动干扰导致大量营养物 质排人水库, 为长寿湖鱼类提供了摄食食物, 这可能是引起 长寿湖水库鳙和鲢 $\delta^{13} \mathrm{C}$ 值较低的主要原因. 王玉玉等研究

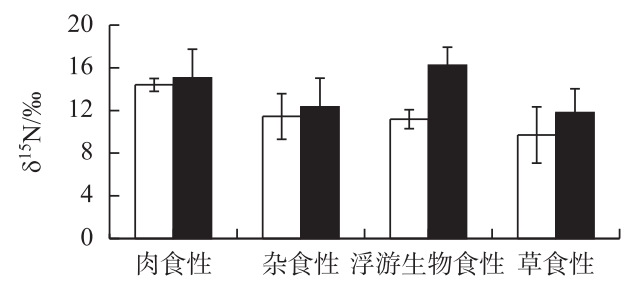

图 2 三峡水库和长寿湖水库不同食性鱼类 间 $\delta^{13} \mathrm{C}$ 和 $\delta^{15} \mathrm{~N}$ 值对比

Fig. 2 Comparison of $\delta^{13} \mathrm{C}$ and $\delta^{15} \mathrm{~N}$ values of fishes in Three Gorges Reservoir and Changshou Reservoir 发现,在鄱阳湖口和鄱阳湖与长江交汇处所采集的短领魰 $\delta^{13} \mathrm{C}$ 值相差较大, 说明不同生活环境中鱼体的食物来源存在较大差异 ${ }^{[9]}$. 三峡水库和长寿湖水库平均 $\delta^{15} \mathrm{~N}$ 值 分别为 $11.98 \% 0 \pm 2.25 \%$ 和 $13.95 \% 0 \pm 3.02 \%$, 长寿湖水库 $\delta{ }^{15} \mathrm{~N}$ 值显著高于三峡水库 $(F=16.61, P<0.01)$. 有研究 表明, 大量含氮生活污水与农业废水的排人影响水体初级食物源的 $\delta^{15} \mathrm{~N}$ 值, 进而对鱼类的 $\delta^{15} \mathrm{~N}$ 值产生影 响 ${ }^{[33-34]}$. 徐军等研究指出人类活动引起的营养输人导致食物网中生物 $\delta^{15} \mathrm{~N}$ 值升高, 本研究也证实了这一结果, 因为长寿湖较高营养水平的水体环境导致其鱼体内 ${ }^{15} \mathrm{~N}$ 的富集也相对较高.

表 3 长寿湖水库鱼类样品的碳、氮稳定同位素比值

Tab.3 Carbon and nitrogen isotopic values of the fish samples from Changshou Reservoir

\begin{tabular}{|c|c|c|c|c|c|c|c|}
\hline \multirow{2}{*}{ 食性 } & \multirow{2}{*}{ 种类 } & \multirow{2}{*}{$n$ /尾 } & \multicolumn{2}{|c|}{$\delta^{13} \mathrm{C} / \%$} & \multicolumn{2}{|c|}{$\delta^{15} \mathrm{~N} / \%$} & \multirow{2}{*}{ 营养级 } \\
\hline & & & 平均值 & 范围 & 平均值 & 范围 & \\
\hline \multirow[t]{3}{*}{ 肉食性 } & 尧嘴红鲌 & 19 & $-23.14 \pm 1.41$ & $-24.94 \sim-20.41$ & $15.07 \pm 3.05$ & $9.41 \sim 19.15$ & $4.48 \pm 0.90$ \\
\hline & 鳜 & 5 & $-22.57 \pm 0.42$ & $-23.32 \sim-22.31$ & $14.99 \pm 1.69$ & $13.80 \sim 17.88$ & $4.46 \pm 0.50$ \\
\hline & 鲶 & 2 & $-22.08 \pm 1.27$ & $-22.98 \sim-21.19$ & $15.10 \pm 0.17$ & $14.98 \sim 15.22$ & $4.49 \pm 0.05$ \\
\hline \multirow[t]{4}{*}{ 杂食性 } & 鲫 & 11 & $-22.10 \pm 0.89$ & $-24.38 \sim-20.59$ & $10.53 \pm 0.96$ & $9.13 \sim 12.38$ & $3.15 \pm 0.28$ \\
\hline & 鲤 & 1 & -23.96 & - & 13.58 & - & 4.05 \\
\hline & 黄颡鱼 & 1 & -23.15 & - & 16.03 & - & 4.77 \\
\hline & 胭脂鱼 & 1 & -21.78 & - & 15.50 & - & 4.61 \\
\hline \multirow[t]{2}{*}{ 浮游生物食性 } & 鳙 & 3 & $-26.12 \pm 0.50$ & $-26.54 \sim-25.56$ & $17.30 \pm 0.75$ & $16.75 \sim 18.15$ & $5.14 \pm 0.22$ \\
\hline & 鲢 & 3 & $-24.50 \pm 0.68$ & $-25.14 \sim-23.79$ & $15.15 \pm 1.77$ & $13.29 \sim 16.80$ & $4.51 \pm 0.52$ \\
\hline \multirow[t]{2}{*}{ 草食性 } & 草鱼 & 5 & $-19.03 \pm 2.29$ & $-22.90 \sim-17.03$ & $12.02 \pm 0.69$ & $11.29 \sim 12.94$ & $3.59 \pm 0.20$ \\
\hline & 武昌鱼 & 3 & $-23.06 \pm 0.74$ & $-23.58 \sim-22.54$ & $11.50 \pm 4.80$ & $6.63 \sim 16.23$ & $3.43 \pm 1.41$ \\
\hline
\end{tabular}

\section{2 鱼类营养级分析}

氮稳定同位素在沿食物链的传递过程中产生分馏, 使得 ${ }^{15} \mathrm{~N}$ 沿食物链在生物体中发生富集, 因此利用 $\delta^{15} \mathrm{~N}$ 值能确定生物的营养级并构建食物网结构 ${ }^{[23]}$. 鱼类摄食习性的不同导致 $\delta^{15} \mathrm{~N}$ 值存在差异, 进而表现为 营养级的不同. 本研究中, 三峡水库鱼类营养级范围为 $2.00 \sim 4.47$, 变化幅度较大, 不同食性鱼类营养级存在 极显著差异 $(F=16.43, P<0.01)$. 其中, 肉食性鱼类平均营养级最高 $(4.19 \pm 0.18)$, 较平均营养级最低的草食 
性鱼类 $(2.81 \pm 0.78)$ 增加了 1.38 , 约提高一个营养级, 而杂食性和浮游生物食性鱼类平均营养级介于两者之 间, 分别为 $3.32 \pm 0.63$ 和 $3.25 \pm 0.26$.

受人为扰动较为严重的长寿湖水库鱼类营养级范围为 $2.00 \sim 5.68$, 其最高营养级显著高于三峡水库 (4.47). 长寿湖水库不同食性鱼类营养级存在极显著差异 $(F=8.34, P<0.01)$, 且最大营养级为浮游生物食 性鱼类 $(4.82 \pm 0.50)$ 而非肉食性鱼类 $(4.48 \pm 0.79)$, 这与当前肉食性鱼类位于水生食物链顶端、营养级最大的 认识不同. 因此, 可推测, 人为活动干扰可能对水生生态系统中鱼类营养级和食物网结构产生了影响. 长寿 湖水库鱼类营养级异常的现象可能与鱼体生存环境和食物来源有关, 不同来源的含氮物质具有不同的 $\delta^{15} \mathrm{~N}$ 值, 长寿湖水库周边居民污水的排放、农业旅游业的发展以及喂养鱼饲料中鱼骨粉的加人均会导致鱼体内 $\delta^{15} \mathrm{~N}$ 值增高, 从而引起营养级异常.

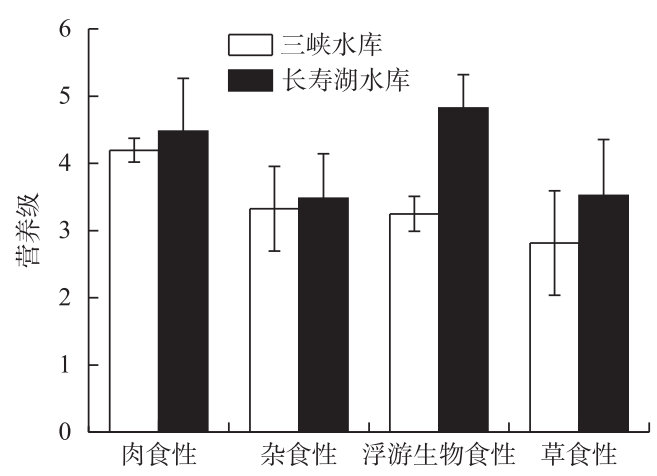

图 3 三峡水库和长寿湖水库不同 食性鱼类间营养级的对比

Fig.3 Comparison with trophic levels of fishes between Three Gorges Reservoir and Changshou Reservoir

三峡水库和长寿湖水库鱼类平均营养级分别为 $3.48 \pm 0.66$ 和 $4.15 \pm 0.89$, 差异极显著 $(F=22.24, P<0.01)$. 长寿湖水库鱼类平均营养级显著高于三峡水库, 不同食 性鱼类的平均营养级也均高于三峡水库, 且长寿湖水库 中营养级最低的草食性鱼类的平均营养级 $(3.52 \pm 0.83)$ 也略高于三峡水库 $(3.48 \pm 0.66)$ ( 图 3). 三峡水库中尧嘴 红鲌的营养级为 $4.14 \pm 0.24$ (表 2), 而长寿湖中尧嘴红鲌 的营养级为 $4.48 \pm 0.90$ (表 3 ). 总体上, 长寿湖鱼类食物 来源中的 $\delta^{15} \mathrm{~N}$ 值高于三峡水库, 且两者的鱼类营养级具 有明显的空间差异, 同一种鱼类在不同生态环境水体中 的营养级位置不同.

此外,由于鱼类生长过程中食性的变化和不同季 节食物来源的变动, 其营养级会受到个体大小的影响. 张波等研究发现, 崂山湾鱼类营养级随体长的增加而 增加 ${ }^{[35]}$; 徐军等也发现体长为 $54 \sim 290 \mathrm{~mm}$ 的湖鲚 $\delta^{15} \mathrm{~N}$ 值与体长之间呈正相关关系 ${ }^{[36]}$. 这与本研究中鱼体营 养级与体长无明显相关性 $\left(r^{2}=0.016, P=0.66\right)$ 的结果

不同,说明本研究区域鱼体的体型对其营养级的差异影响不明显.

\section{3 鱼类食物网结构}

应用 $\delta^{13} \mathrm{C}$ 和 $\delta^{15} \mathrm{~N}$ 值分别构建三峡水库和长寿湖水库鱼类食物网结构 (图 4), 肉食性鱼类长吻鮠 ( L.LO)、鳜 (S.CH)、翘嘴红鲌 (E.IL)、鲶 (S.AS)、鳡 (E.BA) 和鳤 (O.EL) 拥有较高的营养级, 位于食物链的 上层. 草食性鱼类武昌鱼 (M.AM) 、草鱼 (C.ID) $\delta^{15} \mathrm{~N}$ 值相对较低, 位于食物链的较低层. 食物链之间错综复 杂的营养关系形成食物网结构, 三峡水库的食物网结构正常, 且较长寿湖水库的食物网结构复杂 (图 4). 长 寿湖水库受人为活动的干扰, 导致食物网结构发生异常, 浮游生物食性鱼类营养级高于肉食性. 人为氮源的 输人影响水生食物网结构及营养级位置, 导致仅仅通过鱼体 $\delta^{15} \mathrm{~N}$ 值无法准确判断其营养关系. 有研究发现, 脂肪酸在生物摄食活动过程中相对稳定且新陈代谢过程中不易发生变化, 故可作为生物食物源的生物标志 物 $^{[37]}$, 通过对比不同生物脂肪酸组成的差异可以追踪物质在食物网中的传递途径, 将脂肪酸与碳氮稳定同 位素相结合,有利于更准确地判断鱼体营养级和食物网结构.

\section{3 结论}

1 ) 本研究中长寿湖鱼类的 $\delta^{15} \mathrm{~N}$ 值 $(13.95 \% 0 \pm 3.02 \% 0)$ 显著高于三峡水库 $(11.98 \% 0 \pm 2.25 \% 0)$, 说明人类活 动引起的营养物质输人导致食物网中生物 $\delta^{15} \mathrm{~N}$ 值升高.

2) 本研究区域的营养级范围为 $2.00 \sim 5.68$, 人为影响程度较高的长寿湖水库鱼类营养级显著高于三峡 水库, 且长寿湖水库鱼类营养级出现异常现象, 说明对于人为影响较大的水体, 采用 $\delta^{15} \mathrm{~N}$ 值计算不同食性鱼 类间的营养级存在不确定性. 

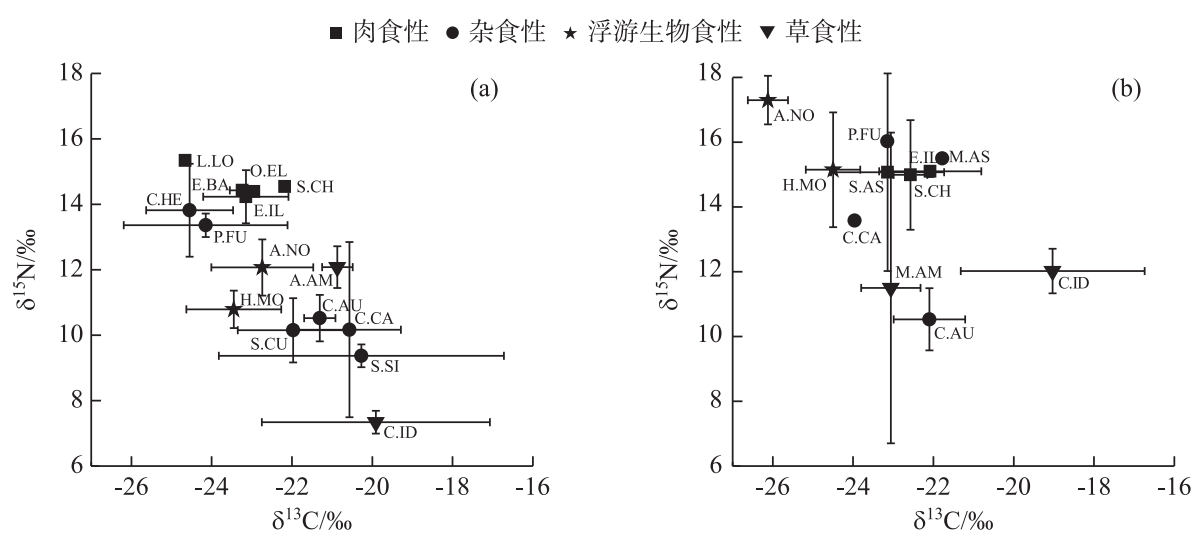

图 4 三峡水库 $(\mathrm{a})$ 和长寿湖水库 $(\mathrm{b})$ 鱼类食物网结构

Fig.4 Food web structure of fishes in Three Gorges Reservoir (a) and Changshou Reservoir (b)

3) 在研究人为干扰较重湖泊的食物网结构、计算鱼类营养级时, 应格外注意稳定同位素比值的含义, 准 确选择基线生物,并考虑鱼类体长因素在营养结构分析中的影响.

\section{4 附录}

附录 I 见电子版( DOI: 10.18307/2019.0321).

\section{5 参考文献}

[ 1 ] Xiao XW, Wang YY, Zhang H et al. Trophic position and its impact on fish in Raohe River during the dry season, Jiangxi Province. Acta Ecological Sinica, 2015, 35(18) : 6216-6223. DOI: 10.5846/stxb201401240180. [肖协文, 王玉玉, 张 欢等. 饶河枯水期主要鱼类营养级位置及其影响因素. 生态学报, 2015, 35(18): 6216-6223.]

[ 2 ] Grey J. The use of stable isotope analyses in freshwater ecology: Current awareness. Polish Journal of Ecology, 2006,54 (54) : 563-584.

[ 3 ] Li YM, Huang XH, Liu CW et al. Application of carbon and nitrogen stable isotope technology in feeding habits. Journal of Guangdong Ocean University, 2007, 27 (4) : 99-103. [李由明, 黄翔鹄, 刘楚吾等. 碳氮稳定同位素技术在动物食 性分析中的应用. 广东海洋大学学报, 2007, 27(4) : 99-103.]

[ 4 ] Xu J, Zhang M, Xie P. Variability of stable nitrogen isotopic baselines and its consequence for trophic modeling. $J$ Lake $S c i, 2010,22$ (1) : 8-20. DOI: 10.18307/2010.0102. [徐军, 张敏, 谢平. 氮稳定同位素基准的可变性及对营养级 评价的影响. 湖泊科学, $2010,22(1): 8-20$.]

[ 5 ] Li ZY, Jin XS, Zhuang ZM et al. Applications of stable isotope techniques in aquatic ecological studies. Acta Ecological Sinica, 2005, 25(11) : 3052-3060. [李忠义, 金显仕, 庄志猛等. 稳定同位素技术在水域生态系统研究中的应用. 生态学报, 2005, 25(11): 3052-3060.]

[ 6 ] Ling JH, Zhang YZ, Wang MH et al. Characteristics of carbon and nitrogen in the downstream columnar sediment of Maozhou River, Shenzhen. Environmental of Science, 2017, 38(12) : 5081-5089. DOI: 10.13227/j. hjkx. 201704285. [凌郡鸿, 张依章, 王民浩等. 深圳茅洲河下游柱状沉积物中碳氮同位素特征. 环境科学, 2017, 38(12): 5081-5089.]

[ 7 ] Zhou ZH, Liu CQ, Li J et al. Record of ecosystem evolvement processes provided by $\delta^{13} \mathrm{C}\left({ }_{\text {org }}\right)$ and $\delta^{15} \mathrm{~N}$ values in Chaohu Lake sediments. Environmental of Science, 2007, 28(6): 1338-1343. [周志华, 刘丛强, 李军等. 巢湖沉积物 $\delta^{13} \mathrm{C}\left({ }_{\mathrm{org}}\right)$ 和 $\delta^{15} \mathrm{~N}$ 记录的生态环境演化过程. 环境科学, 2007, 28 (6) : 1338-1343.]

[ 8 ] Post DM, Pace ML, Hairston NG. Ecosystem size determines food-chain length in lakes. Nature, 2000, 405 (6790): 1047-1049. DOI: 10.1038/35016565.

[ 9 ] Wang YY, Yu XB, Zhang L et al. Food web structure of Poyang Lake during the dry season by stable carbon and nitrogen 
isotopes analysis. Acta Ecological Sinica, 2009, 29(3): 1181-1188. [王玉玉, 于秀波, 张亮等. 应用碳、氮稳定同位 素研究鄱阳湖枯水末期水生食物网结构. 生态学报, 2009, 29(3) : 1181-1188.]

[10] Guzzo MM, Haffner GD, Sorge S et al. Spatial and temporal variabilities of $\delta^{13} \mathrm{C}$ and $\delta^{15} \mathrm{~N}$ within lower trophic levels of a large lake: implications for estimating trophic relationships of consumers. Hydrobiologia, 2011, 675(1) : 41-53. DOI: 10. 1007/s10750-011-0794-1.

[11] Zhang Y, Ding S, Bentsen CN et al. Differences in stream fish assemblages subjected to different levels of anthropogenic pressure in the Taizi River catchment, China. Ichthyological Research, 2015, 62(4) : 450-462.

[12] Kendall C, Silva SR, Kelly VJ. Carbon and nitrogen isotopic compositions of particulate organic matter in four large river systems across the United States. Hydrological Processes, 2010, 15(7) : 1301-1346.

[13] Mariotti A. Denitrification in groundwaters, principles and methods for its identification: A review. Journal of Hydrology, 1986, 88: 1-23.

[14] Kendall C, Aravena R eds. Nitrate isotopes in groundwater systems. Boston: Klumer Academic Publishers, 2000: 261-297.

[15] Zhang H, Xiao XW, Wang YY et al. Spatial variation instable isotope signatures and trophic position of fish in Raohe River, Lake Poyang Basin. J Lake Sci, 2015, 27 (6) : 1004-1010. DOI: 10.18307/2015.0603. [张欢, 肖协文, 王玉玉等. 鄱阳湖流域饶河鱼类稳定同位素比值和营养级的空间变化. 湖泊科学, 2015, 27(6) : 1004-1010.]

[16] Zhou X, Chen G, Shi G et al. The effects of different diet protein sources on carbon and nitrogen isotope fractionation of juvenile cobia Rachycentron canadum L. Journal of Tropical Oceanography, 2014, 33(5): 35-40. [周晖, 陈刚, 施钢等. 不同蛋白源对军曹鱼幼鱼碳、氮稳定同位素分馏的影响. 热带海洋学报, 2014, 33(5) : 35-40.]

[17] Bai WY, Zhang C, Tang ZY et al. Seasonal variations in vertical profile of Hg species and the influential factors in Changshou reservior. Environmental of Science, 2015, 36(10): 2863-2869. DOI: 10.13227/j.hjkx.2015.10.013. [白薇扬, 张 成, 唐振亚等. 长寿湖水库垂直剖面不同形态永的季节变化特征及其影响因素. 环境科学, 2015, 36(10): 2863-2869. ]

[18] Vizzini S, Mazzola A. The effects of anthropogenic organic matter inputs on stable carbon and nitrogen isotopes in organisms from different trophic levels in a southern Mediterranean coastal area. Science of the Total Environment, 2006, 368(2) : 723-731.

[19] Carlier A, Riera P, Amouroux JM et al. Food web structure of two Mediterranean lagoons under varying degree of eutrophication. Journal of Sea Research, 2008, 60(4): 264-275.

[20] Feng X, Meng B, Yan H et al eds. Bioaccumulation of mercury in aquatic food chains. Singapore: Springer, 2018: 339-389.

[21] Editorial board of "Water and wastewater monitoring and analysis method", Ministry of Environmental Protection of the People's Republic of China ed. Monitoring and analysis methods of water and wastewater: fourth edition. Beijing: China Environmental Science Press, 2002. [国家环境保护总局《水和废水监测分析方法》编委会. 水和废水监测分析方 法: 第 4 版. 北京: 中国环境科学出版社, 2002.]

[22] Weng XY, Lin MA, Yan Y. Comparison of determination of phytoplankton chlorophyll a by spectroscopic methods in freshwater. Environmental Monitoring in China, 2009, 25(3): 36-38. [翁笑艳, 林美爱, 严颖. 地表水浮游植物叶绿素 a 测定方法比较研究. 中国环境监测, 2009, 25(3): 36-38.]

[23] Post DM. Using stable isotopes to estimate throphic position: modles, methods, and assumptions. Ecology, 2002, 83(3): $703-718$

[24] Zanden MJV, Rasmussen JB. Primary consumer $\delta^{13} \mathrm{C}$ and $\delta^{15} \mathrm{~N}$ and the trophic position of aquatic consumers. Ecology, $1999, \mathbf{8 0}(4)$ : 1395-1404.

[25] Zanden MJV, Casselman JM, Rasmussen JB. Stable isotope evidence for the food web consequences of species invasions in lakes. Nature, 1999, 401(6752): 464-467.

[26] Huang L, Wu Y, Zhang J et al. Distribution of C, N, P and $\delta^{13} \mathrm{C}$ in aquatic plants of some lakes in the middle Yangtze Valley. Acta Geoscine Sinica, 2003, 24(6) : 515-518. [黄亮, 吴莹, 张经等. 长江中游若干湖泊水生植物体内 C、N、 $\mathrm{P}$ 及 $\delta^{13} \mathrm{C}$ 分布. 地球学报, 2003, 24(6): 515-518.]

[27] Liu YL. On the stable carbon and nitrogen isotope ecology of aquatic macrophytes in Lake Taihu watershed[Dissertation]. Xiangtan: Xiangtan University, 2015. [刘勇丽. 太湖流域水生植物稳定碳氮同位素的生态学研究 [ 学位论文]. 湘 
潭: 湘潭大学, 2015.]

[28] Wen ZR, Xu J, Xie P. Carbon and nitrogen stable isotopes of macrophytes from Lake Taihu. J Lake Sci, 2016, 28 (1): 163-169. DOI: 10.18307/2016.0119. [温周瑞, 徐军, 谢平. 太湖高等水生植物稳定碳、氮同位素特征. 湖泊科学, 2016, 28(1) : 163-169.]

[29] Cao WX. Megalobrama amblycephala and Megalobrama terminalis in Liangzi lake. Acta Hydrobiologica Sinica, 1960, (1) : 57-82. [ 曹文宣. 梁子湖的团头鲂与三角鲂. 水生生物学报, 1960，(1)：57-82.]

[30] Davenport SR, Bax NJ. A trophic study of a marine ecosystem off southeastern Australia using stable isotopes of carbon and nitrogen. Canadian Journal of Fisheries \& Aquatic Sciences, 2002, 59(3) : 514-530.

[31] Fry B ed. Stable Isotope ecology. New York: Springer, 2006: 204-212.

[32] Li ZY. Studies of the feeding ecology of dominant fishes and foodweb structure in the Changjian estuary and southern Yellow Sea with stable isotope[Dissertation]. Xiamen: Xiamen University, 2006. [李忠义. 应用稳定同位素技术研究 长江口及南黄海水域主要鱼类摄食生态和食物网结构 [学位论文]. 厦门: 厦门大学, 2006. ]

[33] Peterson BJ. Stable isotopes as tracers of organic matter input and transfer in benthic food webs: A review. Acta Oecologia International Journal of Ecology, 1999, 20(4) : 479-487.

[34] Lake JL, McKinney RA, Osterman FA et al. Stable nitrogen isotopes as indicators of anthropogenic activities in small freshwater system. Canadian Journal of Fisheries \& Aquatic Sciences, 2001, 58(5) : 870-878.

[35] Zhang B, Yuan W, Dai FQ. Study on feeding ecology of fish community in Laoshan Bay during summer using stable carbon and nitrogen isotopes. Journal of Fisheries of China, 2016, 40(4) : 585-594.

[36] Xu J. Ecological studies on the food web structures and trophic relationships of freshwater lakes in china using stable carbon and nitrogen isotopes[Dissertation]. Wuhan: Institute of Hydrobiology, Chinese Academy of Sciences, 2005. [徐军. 应 用碳、氮稳定性同位素探讨淡水湖泊的食物网结构和营养级关系 [学位论文]. 武汉: 中国科学研究生院水生生物 研究所, 2005.]

[37] Huang L, Wu Y, Zhang J. Studies on nutrient relation of aquatic ecosystem using fatty acids. Marine Sciences, 2009, 33 (3) : 93-96. [ 黄亮, 吴莹, 张经. 脂肪酸标志水生生态系统营养关系的研究. 海洋科学, 2009, 33(3) : 93-96.] 


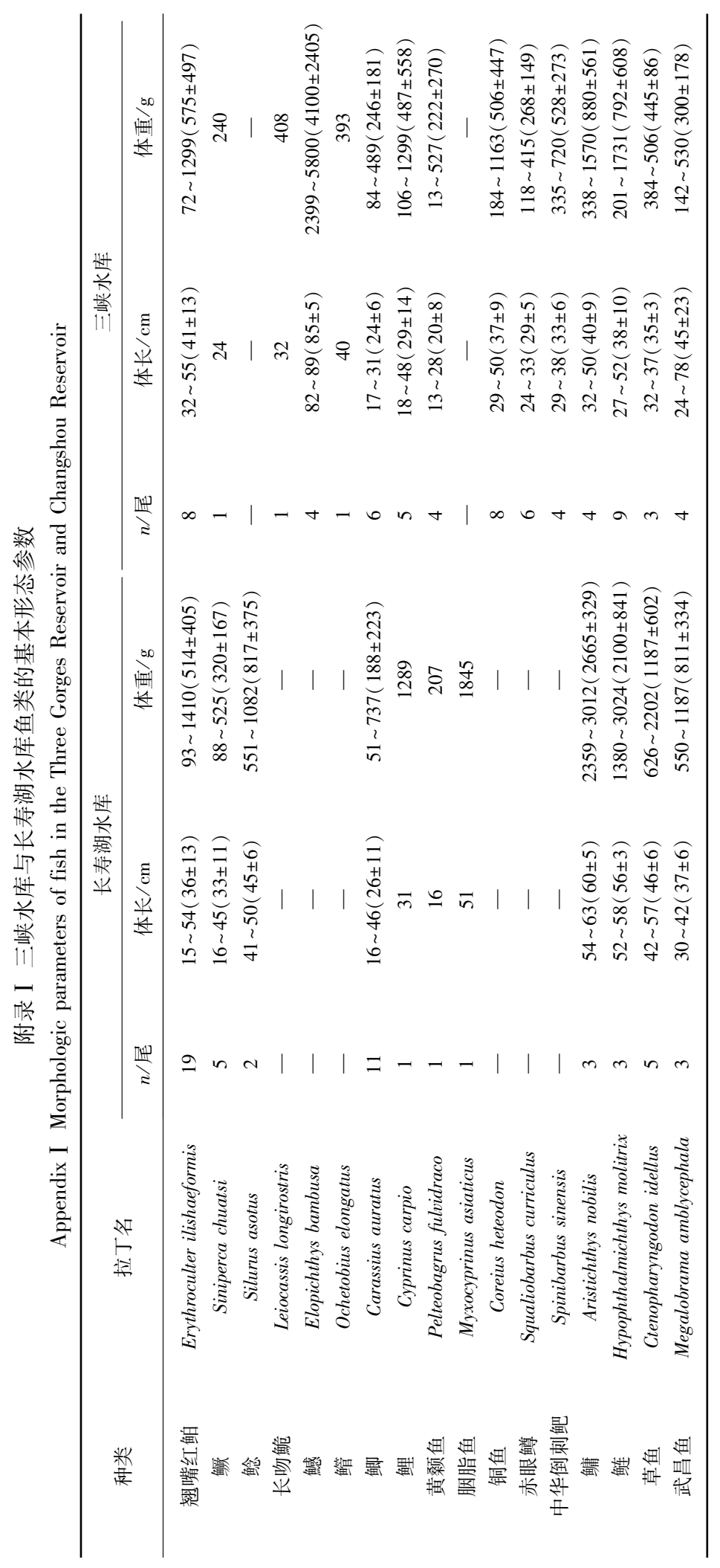

